\title{
ENTREVISTA
}

\section{Entrevista com o Ministro Aluízio Alves}

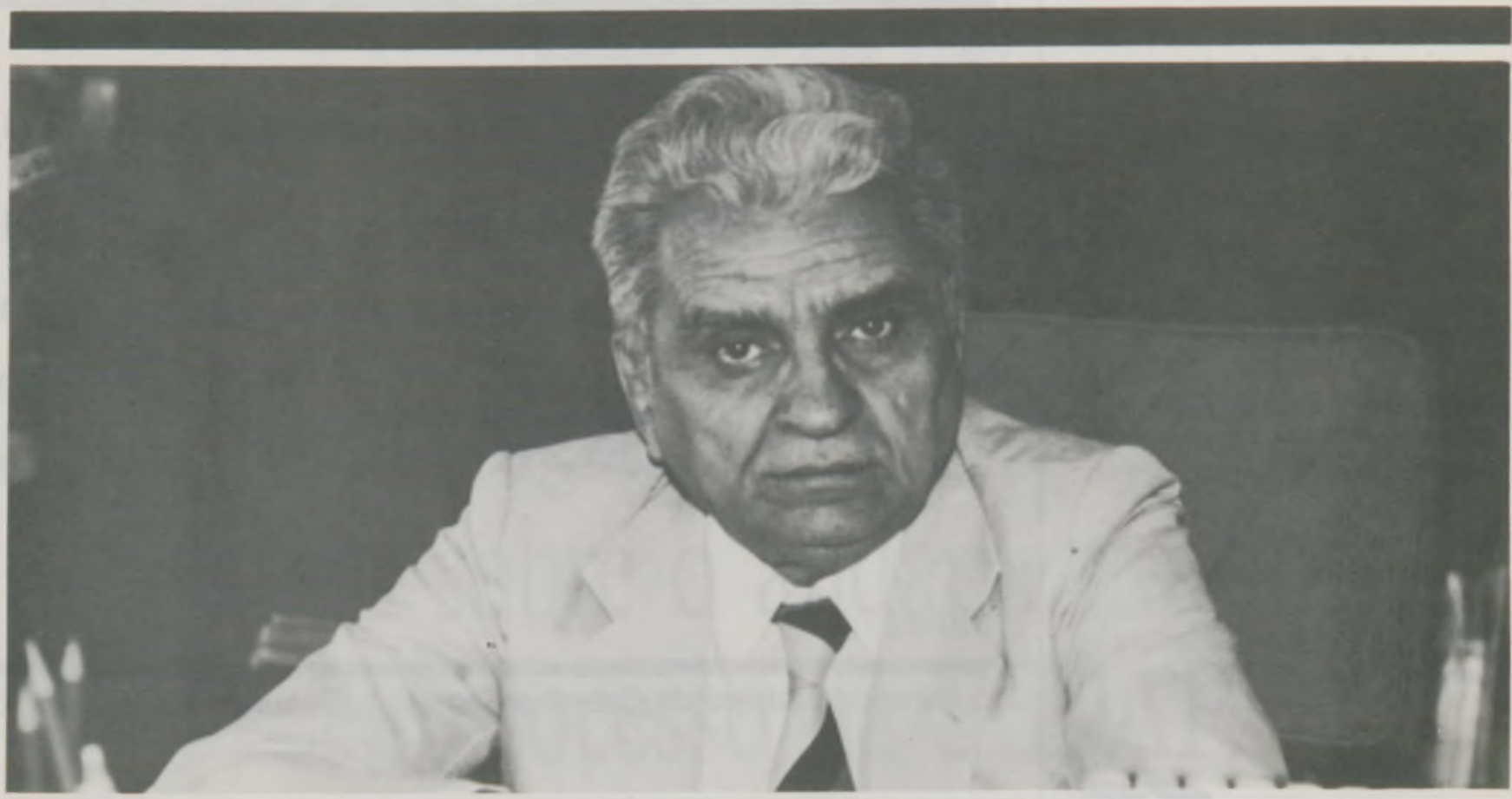

Nesta entrevista à Revista do Serviço Público, o ministro Aluizio Alves, da Administração, anuncia a abertura do vestibular da Escola Nacional de Administração Pública, em todo o país mediante convênio firmado com a Cesgranrio e explica as diversas etapas da Reforma Administrativa, tais como o Plano de Carreira, a ascensão funcional especial, a movimentação interinstitucional de servidores e os reajustes de salário concedidos recentemente.

O ministro afirma que, ao contrário do que muita gente imagina, Reforma Administrativa não signıfica necessariamente redução de pessoal e extinção de órgãos, podendo até ocorrer exatamente o contrário. O que importa é lornar a Administraçāo Pública eficiente e adequada às necessidades do Pais.

O Brasil, disse o ministro, tem um dos menores quadros de pessoal no serviço público em relação à sua população e dimensão territorial. A entrevista é a seguinte:
P - Ministro, o Cadastro Nacional de Pessoal Civil - CNPC - foi concluído em outubro e entregue ao Presidente Sarney. Quantos funcionários ociosos existem? O Governo precisa demitir?

M - Para boa parcela da República quando se fala em Reforma Administrativa pensa-se em reduzir o número de repartições: extinguir órgãos do Governo; demitir cem ou duzentos mil funcionários. E todo mundo pensa que a partir daí a administração vai andar muito bem. Reforma Administrativa não é nada disso. Reforma pode ser a diminuição ou acréscimo de órgãos, de repartições, a redução ou aumento de funcionários. A Reforma Administrativa é um processo lento, demorado. É complexo que racionaliza a administração para que ela funcione melhor e transparentemente, dando a satisfação ao contribuinte de oferecer um serviço de melhor qualidade.

P - Quase diariamente acusam o serviço público de ineficiência. Como o senhor reage a esta tese?
M - É inegável que o serviço público é lento e complicado, precisa de eficiência. Então, o que nós estamos visando na Reforma Administrativa, não é uma mágica, não é um milagre. É o início de um processo que será realizado por esse Governo, pelos próximos Governos até que a Administração Pública brasileira alcance um nível de qualidade satisfatória para a sociedade que ela vai servir.

$\mathrm{P}$ - O que a administração pretende fazer para modificar essas imagens do serviço público?

M - Temos três objetivos paralelos em execução: - A reformulação das estruturas: algumas delas já foram reformuladas. O Itamaraty, com a redução de vinte Departamentos no Brasil e a extinção de dezoito Consulados no exterior; o IBC, com a redução de várias estruturas e do número de funcionários de 4.400 para 2.200. No IBC, é provável que ainda se reduza mais, à medida que a iniciativa privada na área do café vá assumindo novas responsabilidades. A Superintendência do 


\section{ENTREVISTA}

Desenvolvimento da Borracha (SUDHEVEA) reduziu de 640 para 120 funcionários, extinguindo vários escritórios desnecessários, e hoje, ela é uma estrutura enxuta, pequena e capaz de incentivar a produção da borracha, evitando o desestímulo do produtor nacional. E além disso, já fizemos reformas parciais das estruturas do Ministério da Saúde, extinguindo as delegacias federais que se tornaram desnecessárias, sobretudo a partir do momento em que o INAMPS, Secretaria da Saúde e Ministério da Saúde, se entenderam para uma ação em comum.

Fizemos a reformulação dos órgãos do Ministério da Cultura, eliminando vários deles, retirando a Embrafilme, retirando o Estado de certas tarefas que não eram adequadas, e reunindo em torno de três fundaçōes, serviços que eram dispersos e difíceis de coordenar e, nesse sentido, nós estamos na segunda tarefa paralela.

P - O que a SEDAP está fazendo para evitar desperdício de material no serviço público?

M - Nós estamos fazendo um levantamento já há algum tempo, e agora vamos começar o levantamento na parte de serviços gerais: tudo que diga respeito a serviço público, patrimônio da União e organização de material será reunido num catálogo com vistas a racionalizar as compras do serviço público, evitando gastos desnecessários.

P - Como o senhor analisa a instituição do Sistema de Carreira do Pessoal Civil da União?

M - Essa é a parte que eu considero mais importante da reforma administrativa: a organização dos quadros de pessoal através de um sistema de carreiras. Atualmente nós temos carreira no fisco, no Ministério da Fazenda, estamos implantando carreira no Ministério do Planejamento, temos carreira antiga na Polícia Federal e também no Itamaraty, que já foi reformulada desde a reforma administrativa. Mas temos todos os outros órgãos, todos os outros setores, abrangendo praticamente quatro quintos ou mais do funcionalismo sem carreiras, porque as tentativas feitas em 1936, repetidas depois em 1960 e 70, todas elas foram bem intencionadas, mas não correspondem técnica e doutrinariamente às estruturas de carreira, às necessidades de carreiras e, sobretudo, a possibilidade do funcionário, pelo seu próprio mérito, fazer sua carreira.

P - Mas já existe a instituição do "padrinho" forte, do julgamento subje- tivo do chefe. E como ficam estas "instituiçōes"?

$\mathrm{M}-\mathrm{O}$ que é importante numa carreira é dar perspectiva ao funcionário e fazer com que essa perspectiva seja realizada pelo seu próprio mérito e não através de pistolão, de favoritismo, do julgamento subjetivo dos chefes de serviço. Não através apenas da antigüidade, que não é condição de mérito. Então o que nós precisamos, e estamos fazendo, é criar um sistema em que o funcionário possa fazer a sua carreira, a sua vida, através do seu próprio mérito. $E$ isso, ele só poderá fazer agora, porque só agora ele vai dispor de meios para isso. Primeiro, através da Escola Nacional de Administração, que além de um curso de altos estudos para formar lideranças administrativas, vai realizar cursos necessários a promoçōes de funcionários de nível superior, e também através do CEDAM - Centro de Desenvolvimento Administrativo - que, em convênio com as universidades federais, vai realizar também cursos necessários à promoção de funcionários de nivel médio.

P - Isso já significa a conclusâo da reforma administrativa no setor de pessoal?

M - Agora, nós estamos com os primeiros elementos, as primeiras condições realmente, para fazer um sistema de carreiras, e isso foi objeto de mensagem do Presidente Sarney ao Congresso Nacional com pedido de urgência. No Congresso, tudo foi encaminhado pelo relator, deputado Juthay Júnior, e com isso, nós esperamos ter uma lei que fixe as diretrizes do sistema de carreiras nos permitindo, no começo do ano, ter um Plano de Retribuiçōes de Cargos e Salários e o Estatuto do Funcionário Público, definindo o regime jurídico do funcionalismo e, a partir dai, fazermos uma organização adequada e apropriada para o serviço público brasileiro.

P - Este aumento salarial, Ministro, que foi dado agora aos servidores civis, é realmente igual ao dos militares? E por que este aumento só foi escalonado para os funcionários civis?

$\mathbf{M}$ - Foi escalonado porque para os civis de nível médio o aumento precisava ser maior do que para os de nivel superior. E os militares, tendo carreira organizada, puderam dar 33\% a todos - do General ao Soldado - . E se nós fôssemos dar $33 \%$ a todos, o que aconteceria? Aqueles que já tinham conseguido melhores vantagens, como os consultores jurídicos da União, as tabelas de especialistas, os funcionários das universidades, se- riam altamente beneficiados. $\mathrm{E}$ aqueles que não tiveram esses benefícios anteriores, seriam sensivelmente prejudicados. Então, fizemos o seguinte: os militares tiveram condições financeiras para dar $33 \%$ do general ao soldado, do almirante ao fuzileiro, do brigadeiro ao soldado da Aeronáutica. Nós tivemos a mesma importância, ou seja: $33 \%$. E demos $45 \%$ ao nivel médio, que representa $60 \%$ do funcionalismo. E demos a $90 \%$ do pessoal de nivel superior, $35 \%$. Portanto, mais do que receberam os militares. Agora, como é que nós, tendo apenas o direito de dar $33 \%$ como os militares, conseguimos dar $45 \%$ a $60 \%$ do funcionalismo que é de nivel médio e $35 \%$ a $90 \%$ do pessoal de nivel superior? Os $10 \%$ de nivel superior que não receberam os $35 \%$ e boa parcela dos de nivel médio que, já haviam sido beneficiados no decorrer do ano com outros reajustes, tiveram percentuais menores que complementaram os $35 \%$.

P - As metas programadas pelo seu ministério serão alcançadas neste governo?

$\mathbf{M}-$ Eu acho o seguinte: em matéria de estruturas nós conseguimos muito para um mandato de 4 anos. Esse é um trabalho lento, complexo, e enfrenta muitas inércias, muitos interesses, muitas resistências. Em matéria de pessoal nós conseguiremos implantar o sistema de carreiras e neste ano, implantar o maior número de carreiras possivel, porque cada ministério terá sua carreira. Em termos de material e serviços gerais, como dissemos antes, estamos trabalhando. Nós gastamos muito tempo fazendo diagnósticos. Nenhum governo do Brasil sabia quantos funcionários públicos tinha a União. Só agora, concluído o primeiro cadastro, nós sabemos quantos funcionários existem. Nós não sabíamos qual era a política de salários. Todos os paises têm em geral, seis ou sete gratificaçōes, o Brasil tem 96. Então, vez por outra, nós vamos descobrindo órgão de segundo escalão que tem gratificação criada ilegalmente pela sua diretoria. Nós, assim, perdemos muito tempo. Agora é que nós temos um quadro exato das gratificações e das correções que precisam ser feitas. Nós tínhamos distorçōes muito grandes: os funcionários estatutários não tinham o $13^{\circ}$. salário, trabalhavam as vezes na mesma sala, na mesma repartição que um CLT e quem sabe se o funcionário estatutário era mais assíduo ou mais competente que o outro? E sempre chegava o mês de dezembro, o CLT tinha dinheiro para a sua ceia de Natal e o outro não. Portanto, todas as distorções 
tiveram que ser levantadas, corrigidas, tivemos que lutar contra elas. Agora sim, estamos elaborando o primeiro projeto do Plano de Cargos e Salários, a politica de salário. Estamos agora organizando e pondo para funcionar a Escola Nacional de Administração, cujo vestibular já foi marcado.

$\mathrm{P}$ - Ministro, qual a relação entre o número de funcionários públicos no Brasil e sua população?

$\mathrm{M}$ - Se você comparar com outros países do Mercado Comum Europeu, por exemplo, o país que tem menor número de funcionários em relação a população, tem $4,7 \%$. Isso em países pequenos. $O$ Brasil, com toda complexidade de um continente, tem apenas $1,5 \%$ de funcionários. Então, não há excesso de funcionários. Agora, há órgãos que têm funcionários demais, e outros que têm carência de funcionários. Portanto, nós estamos propondo ao Presidente, e eu acredito que ele remeta ao Congresso dentro de poucos dias, a lei que permite a movimentação de funcionários da administração direta para a indireta e da indireta para a direta.

$\mathrm{P}$ - Como tem sido feita essa movimentação?

M - Dentro da administração direta, dentro dos ministérios e órgãos a eles vinculados, inclusive as autarquias, nós já podemos fazer essa movimentação legalmente, e já fizemos. Nós, no governo Sarney, tivemos 31.072 vagas. Por morte, por aposentadoria, pedido de demissão ou demissão, nós conseguimos preencher apenas 13.000 , porque as outras se tornaram desnecessárias. Nós agora analisamos, porque antigamente, quando surgia uma vaga, imediatamente se fazia a substituição. Agora não. O caso vem para a Secretaria de Administração. Aqui nós temos um trabalho antigo de lotação. A lotação das repartiçōes é de 1970. Nestes 17 anos, o Brasil cresceu, algumas repartiçōes cresceram, outras diminuiram de função, e nós continuamos com a lotação de 1970 . Só em dezembro do ano passado, nós conseguimos criar as auditorias de pessoal por decreto. Ainda este ano, criamos os dois primeiros cursos de auditores e já formamos 80. E agora é que nós estamos revendo a lotação de cada órgão. Mesmo assim, sem ter ainda um trabalho racional de lotação, nós conseguimos: primeiro, das 31 mil vagas, só preenchemos $13 \mathrm{mil}$, pois verificamos a desnecessidade para aqueles órgãos de preencher aquelas vagas. Segundo, conseguimos movimentar, dentro da administração direta, 4.400 fun- cionários: mais ou menos 2.000 do IBC, $400 \mathrm{da}$ SUDHEVEA e de outros órgãos, de modo que estamos começando a organizar, mas encontramos uma dificuldade: enquanto que na administração direta nós temos apenas $\mathbf{5 7 0}$ mil funcionários, em alguns desses órgãos ainda há excesso, mas na maioria há falta. Na administração indireta nós temos um milhão e seis mil funcionários e eu acho que aí é onde existe uma certa margem de excesso setorial. Então, nós estamos pleiteando ao Presidente, um projeto de lei a ser encaminhado ao Congresso, que permita também essa movimentação da administração direta para a indireta e vice-versa. Com isso e com as auditorias de pessoal que nós estamos fazendo agora para atualizar lotaçōes que eram de 1970 e que nós vamos atualizar dentro das necessidades atuais, nós esperamos: primeiro fazer a movimentação de todos os excessos para onde haja carência e onde houver então necessidade, nós começaremos a convocar, já dentro do sistema de carreira os funcionários concursados.

P - Ministro, as Associações de Funcionários Públicos têm reivindicado a ascensão especial do servidor de nível médio. Como o senhor pretende atender a esta reivindicação?

M - Vamos colocar a verdade em primeiro lugar. Quem inventou essa ascensão funcional especial não foi nenhuma associação de funcionários e sim o Ministério da Administração. Da mesma maneira, acho engraçado quando leio o manifesto dos associados dizendo: "creche já", como se o governo estivesse negando creches. Em 1952, quando se fez o estatuto do funcionário público estabeleceuse que nas repartições seriam feitas creches para os filhos dos funcionários. Passou $52,60,65,70,75,80,85$ e nunca associação de funcionário nenhuma reivindicou a creche. Em dezembro passado, revendo o estatuto do funcionário para a atualização que vamos fazer, descobri que existia aquela coisa não cumprida. O governo tinha, em 52, estabelecido a creche e não cumpriu. E aí eu consegui com o Presidente Sarney um decreto regulamentando a creche.

$\mathrm{P}$ - E quando os funcionários poderão contar com as creches e com a ascensão especial?

M - Estamos implantando as creches, contratando creches particulares para atender aos funcionários e, algumas associaçōes de funcionários reivindicam, "creche já", como se fosse uma reivindicação deles não cumprida pelo governo, quando foi uma decisão espontânea do atual governo que nunca tinha sido reclamada pelas associações. Segundo lugar, não foi pleito dos funcionários, ou de nenhuma associação de funcionários. A ascenção funcional especial, foi uma invenção, uma iniciativa do Ministério da Administração, comunicada pela imprensa, e aí sim, os funcionários começaram a fazer esse movimento, portanto, vamos colocar claramente esse assunto. Nós achamos que temos uma grande responsabilidade. Nós não podemos pegar um funcionário que é, muitas vezes escriturário, e se formou em medicina, e de uma hora para outra dizer assim: bom, você agora vai ser médico e empregar ele, porque nós não sabemos se ele pode ser um excelente escriturário porque fez concurso para isso, mas pode ser um bom médico só porque ele tem diploma. Não vamos entregar a saúde do povo a um médico eventualmente desempregado. Nós não podemos pegar um funcionário que é agente administrativo e, só porque ele fez um curso de engenharia e dizer: você agora vai ser engenheiro, entrega a ele a construção de uma ponte e amanhã ela pode cair. O que é nós estamos querendo é o seguinte: dar uma oportunidade aos funcionários de nível médio. Se eles depois que entrarem no serviço público, ou mesmo quando entraram já tinham o nivel superior, que eles tenham oportunidade de passar por um processo seletivo, por exemplo, se ele é médico, ele terá que fazer um estágio num hospital oficial, supervisionado, para que tenhamos consciência de que ele é realmente um médico formado, capaz de exercer a sua profissão. Se engenheiro, um estágio no Ministério dos Transportes para saber se ele está em condições realmente de ter a ascenção de agente administrativo para engenharia se ele passar por certas provas escritas e orais, a mesma coisa para os formandos em direito e outras profissões.

P - Ministro, o que aconteceu com os arquivistas?

M - Em 1979 foi votada uma lei reconhecendo a profissão de arquivista como de nível superior. $\mathrm{O}$ que eu acho uma precipitação, porque no Brasil só existem três cursos de arquivista. Portanto, esses três cursos não tinham condição de formar arquivistas de nivel superior. Em 1982, no governo Figueiredo, foi feita a regulamentação daquela lei que foi ao Congresso e que foi sancionada pelo Presidente no serviço público. E aí abriu-se uma brecha: a lei falava só em quem tivesse nivel superior - a brecha na regu- 


\section{ENTREVISTA}

lamentação: "ou que tenha mais de cinco anos de serviço em arquivo". O que aconteceu? Nós fizemos um levantamento nos arquivos da administração pública federal. Existiam apenas 4.100 funcionários trabalhando em arquivo, mas o decreto diz que para o sujeito requerer seu enquadramento de nível superior, o que Ihe garante uma gratificação de $80 \%$, ou seja, o dobro do seu salário. Basta apresentar um atestado de que ele trabalhava em arquivo, levar à delegacia do Ministério do Trabalho, obter a caderneta como arquivista e pedir o seu enquadramento. De uma hora para outra, tendo as repartições apenas 4.100 arquivistas, requereram enquadramento 49.300 funcionários.

$\mathrm{P}$ - E o que o senhor pretende fazer?

M - Nós fomos examinar. Eram motoristas, contínuos, faxineiros, agentes de vigilância, todos com o atestadozinho de que trabalhavam em arquivo, todos com a cadernetinha de trabalho muito bonitinha dizendo que eles eram arquivista e tal, e muitos deles nâo tinham sequer o segundo ano primário. O que aconteceu? Nós pedimos ao Ministério do Trabalho para sustar o fornecimento daquelas cadernetas até uma decisão nossa, porque do contrário iria para 100 mil. Só no Rio de Janeiro eram 23 mil arquivistas num só órgão. Numa autarquia eram 2.300 , e estamos examinando. Quando o funcionário tem realmente curso superior de arquivista, nós enquadramos. Quando mesmo não tendo o curso, de acordo com o decreto, tem mais de cinco anos de exercicio de arquivo e conhecimentos próprios para executar aquela tarefa, nós enquadramos. E aos outros nós estamos negando, e por isso estamos encontrando uma certa resistência, alguns já foram até para o poder judiciário, mas nós só enquadraremos aqueles que realmente tiverem condições de exercer a profissão de arquivista de nivel superior.

$\mathrm{P}$ - É verdade que a Lei do Sistema de Carreira eliminará $95 \%$ dos cargos em comissão?

M - Com o sistema de carreira, os cargos em comissão serão reduzidos a $5 \%$. Nós vamos ter ministro, secretário-geral, alguns assessores em número limitado e secretários técnicos de serviço. Aqueles que devem executar a política do governo, são aqueles que devem governar o país. Hoje é o PMDB/PFL, amanhã pode ser outro partido, então cada governo, cada partido, tem sua política, seu programa. O resto é carreira, em que o funcionário entra como contínuo e pode chegar a diretor, conforme os cursos e a ca- pacidade que revele. Agora, nós não podemos também desconhecer que há numerosos funcionários que exercem cargos em comissão há muitos anos, e de uma hora para outra, eles não podem ir para a rua. Até porque, como acontece com o dentel, por exemplo, 79 engenheiros que por falta de emprego de engenheiros eram nomeados para cargos $\mathrm{em}$ comissão: FAS, DAS, embora exercessem a função de engenheiros no interior do país. Então, a essas pessoas, nós vamos dar a oportunidade de, mediante um rigoroso processo seletivo, se revelarem capacidade e mérito, serão enquadrados.

P - Como funcionará a ENAP?

M - A Escola Nacional de Administração Pública foi criada no ano passado. Nós conseguimos instalá-la na sede da FUNCEP, e ela está pronta para iniciar as aulas. Já anunciamos a data do vestibular que será feito em três etapas em todo país. Não tínhamos ainda estrutura para fazer no país todo, mas não queríamos privar o funcionário do Acre, Belém, Amapá. Então fizemos um contrato com a Cesgranrio para esse primeiro vestibular. Estamos abrindo em todo país, no mesmo dia e, ao vestibular podem concorrer pessoas que não são funcionários, mas que têm o curso superior, ou pessoas que, já sendo funcionários, embora não tendo curso superior tenham exercido por mais de cinco anos funções de chefia. Is- so é para dar oportunidade ao atual funcionalismo que muitas vezes tem a experiência, mas não teve oportunidade de concluir um curso superior. Não há com isso, nenhum risco de diminuir o nível do curso porque esse funcionário tem o direito de entrar no vestibular, mas só entrará na escola, se passar no vestibular.

P - As Associações dos Servidores reclamam que o governo Sarney provocou prejuízos aos deficientes que teriam sido favorecidos no governo passado. Como é que o senhor explica isso?

M - Esse assunto eu gostaria de esclarecer, porque há um equívoco total. No governo Figueiredo não houve esse decreto. Esse decreto é do Presidente Sarney. $\mathrm{O}$ que aconteceu foi o seguinte: nós encontramos uma grande defasagem entre funcionários aposentados e os funcionários em atividade. Então, no primeiro reajuste que o Presidente Sarney deu, ele acrescentou 10,8\% aos aposentados e, o Tribunal de Contas achou que aquilo era ilegal, era inconstitucional, porque aposentado não pode ganhar mais que o funcionário em atividade. $E$ recusou isso. Nós argumentamos, e o Tribunal reconheceu que aquilo era apenas uma reposição de parte do que tinha sido negado ao aposentado. E as repartições já começaram a pagar. Mas foi iniciativa do Presidente Sarney, não do governo passado.

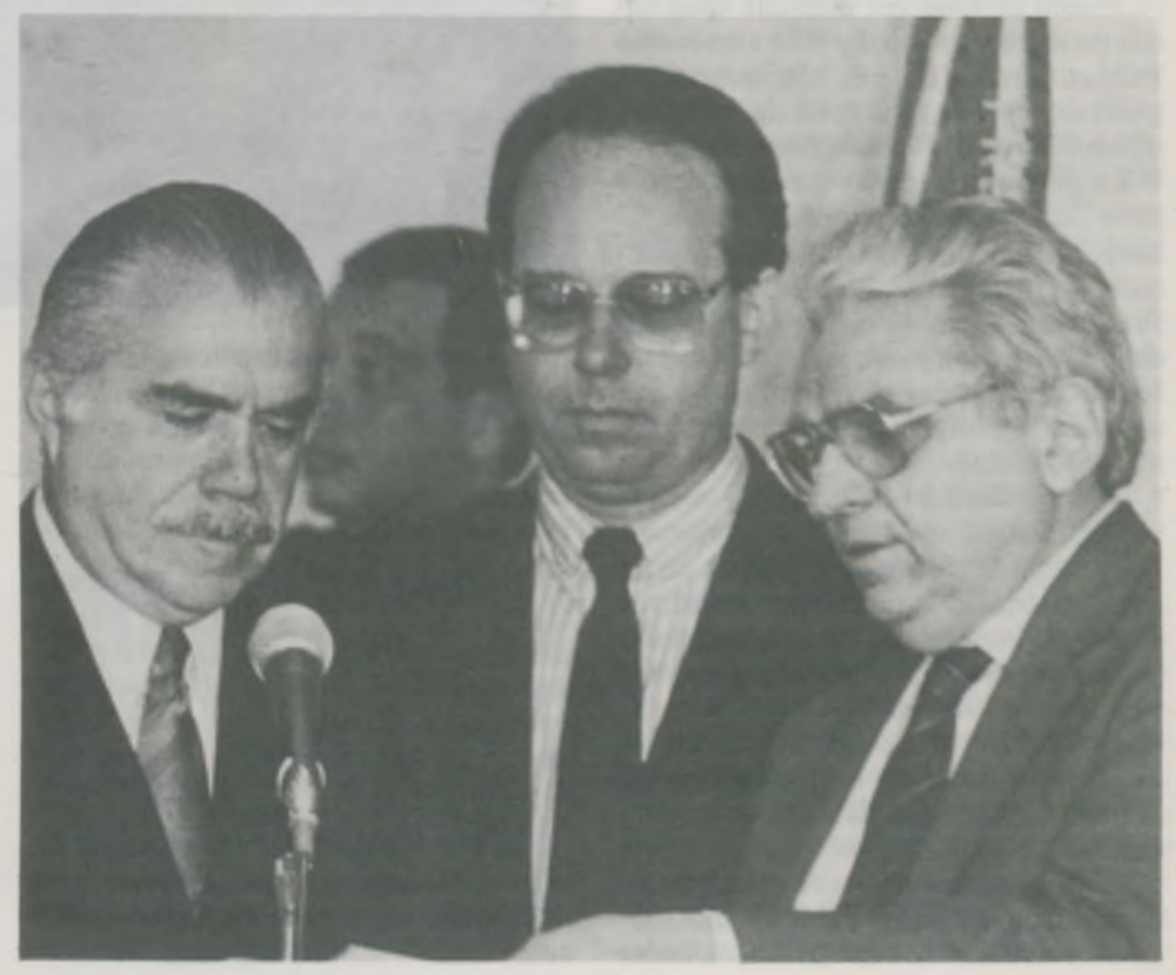

